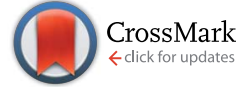

Cite this: Chem. Sci., 2015, 6, 360

Received 31st August 2014 Accepted 3rd October 2014

DOI: $10.1039 / \mathrm{c} 4 \mathrm{sc} 02664 \mathrm{k}$

www.rsc.org/chemicalscience

\section{Conducting polyfurans by electropolymerization of oligofuranstt}

Dennis Sheberla, $\S^{\star}$ Snehangshu Patra, Yair H. Wijsboom, Sagar Sharma, Yana Sheynin, Abd-Elrazek Haj-Yahia, Adva Hayoun Barak, Ori Gidron and Michael Bendikov 9

Polyfurans have never been established as useful conjugated polymers, as previously they were considered to be inherently unstable and poorly conductive. Here, we show the preparation of stable and conducting polyfuran films by electropolymerization of a series of oligofurans of different chain lengths substituted with alkyl groups. The polyfuran films show good conductivity in the order of $1 \mathrm{~s} \mathrm{~cm}^{-1}$, good environmental and electrochemical stabilities, very smooth morphologies (roughness 1-5 nm), long effective conjugation lengths, well-defined spectroelectrochemistry and electro-optical switching (in the Vis-NIR region), and have optical band-gaps in the range of $2.2-2.3 \mathrm{eV}$. A low oxidation potential needed for polymerization of oligofurans (compared to furan) is a key factor in achievement of improved properties of polyfurans reported in this work. DFT calculations and experiments show that polyfurans are much more rigid than polythiophenes, and alkyl substitution does not disturb backbone planarity and conjugation. The obtained properties of polyfuran films are similar or superior to the properties of electrochemically prepared poly(oligothiophene)s under similar conditions.

\section{Introduction}

The field of conjugated and electrically conducting polymers continues to attract much attention both scientifically and technologically. ${ }^{1}$ Among them, an important class of fivemembered unsaturated heterocyclic polymers, such as polypyrrole (PPy), ${ }^{2}$ polythiophene (PT), ${ }^{3}$ polyselenophene $(\mathrm{PSe})^{4}$ as well as their derivatives, have been extensively studied and applied. Polyfuran ( $\mathrm{PFu}$ ), on the other hand, has scarcely been explored and has not been established as a conductive polymer. This is because of the difficulty in polymerization, the low stability and the poor properties of the polyfuran samples that have been obtained. ${ }^{5}$ The reported electrical conductivities of doped polyfurans were measured in the range of $10^{-5}$ to $10^{-2} \mathrm{~S}$ $\mathrm{cm}^{-1,5,6}$ which is significantly lower than the conductivity of polythiophenes electrochemically prepared from a terthiophene $\left(\mathrm{PT}_{3}\right)\left(10^{0} \mathrm{~S} \mathrm{~cm}^{-1}\right)^{3 b, 7}$ and thiophene monomers $\left(10^{2} \mathrm{~S} \mathrm{~cm}^{-1}\right) .^{3 b, 8}$ Polyfurans have also been reported as environmentally and electrochemically unstable. For example, the authors noticed

Department of Organic Chemistry, Weizmann Institute of Science, Rehovot, 76100, Israel

$\dagger$ This work is dedicated to the memory of Professor Michael Bendikov.

\$ Electronic supplementary information (ESI) available: Full experimental and computational details, synthesis of 1-18, Fig. S1-S26 and Tables S1-S4. See DOI: $10.1039 / \mathrm{c} 4 \mathrm{sc} 02664 \mathrm{k}$

§ Current address: Department of Chemistry, Massachusetts Institute of Technology, 77 Massachusetts Avenue, Cambridge, Massachusetts 02139, US. E-mail: denn@mit.edu

ๆ Deceased July 2, 2013. that upon exposure to ambient light and air, films of chemically prepared alkylated polyfuran bleached over a period of hours to days. ${ }^{9}$ Furthermore, the electrochemical redox activity of polyfuran was shown to degrade during cycling in acetonitrile (ACN) solution. ${ }^{10}$

Many researchers have tried to overcome preparation problems by varying the conditions of polymerization..$^{5,11}$ The main problem associated with electrochemical polymerization is the high oxidation potential required to polymerize furan, which results in irreversible over-oxidation of the resulting polyfurans. ${ }^{5,12}$ A mixture of trifluoride diethyl etherate and ethyl ether (BFEE/EE) as a solvent was used to reduce this electropolymerization potential. ${ }^{11, \boldsymbol{d}, \boldsymbol{1 3}}$ However, the reported conductivities of the resulting polyfurans were small (up to $10^{-2} \mathrm{~S}$ $\left.\mathrm{cm}^{-1}\right)$, and their absorption spectra $\left(\lambda_{\max }=420 \mathrm{~nm}\right)^{11 d}$ reveal a short conjugation length of about eight furan rings. ${ }^{14}$ Kanatzidis et al., used terfuran as the starting monomer to lower the potential needed for polymerization to less than $1.0 \mathrm{~V}$ ( $v s$. SCE) ${ }^{11 b}$ The resulting polyfuran was characterized by a variety of techniques and showed a red shifted absorbance maximum centered at $468 \mathrm{~nm}$. Nevertheless, the polyfuran produced had a low conductivity of $2 \times 10^{-3} \mathrm{~S} \mathrm{~cm}^{-1}$, which is probably due to defects in the polymer, as were observed by IR spectroscopy. Chemically synthesized polyfuran did not appear to be highly conjugated because of a significant degree of furan ringopening defects. ${ }^{9,15}$ It is noteworthy that in contrast to polyfurans, the incorporation of furan blocks in conjugated polymers resulted in high quality materials. ${ }^{16}$ Overall, despite numerous reports on the preparation of polyfuran (usually 
lacking full characterization), ${ }^{5}$ it appears that there are no reports of polyfurans with properties such as high conductivity, stability, high conjugation length and small number of defects, all of which are required for their application as organic electronic materials.

We previously reported the preparation of long unsubstituted $\alpha$-oligofurans $\left(\mathrm{Fu}_{5}-\mathrm{Fu}_{9}\right)$ and recently alkyl substituted $\alpha$-oligofurans $\left(\mathrm{Fu}_{n}-2 \mathrm{C}_{6}(n=4,6,8)\right.$ and $\left.\mathrm{Fu}_{16}-6 \mathrm{C}_{6}\right)$ that exhibit higher fluorescence, better packing, greater rigidity, and higher solubility than the corresponding oligothiophenes. ${ }^{\mathbf{1 4 , 1 7}}$ We also showed that these oligofurans display good electronic properties, e.g., field effect mobilities and on-off ratios, similar to those of the corresponding oligothiophene analogues. ${ }^{18}$ Thus, we surmised that polyfurans would not only possess similar properties, but would have advantages over other conductive polymers. The rigidity of their backbone is expected to enable the introduction of large side substituents without breaking planarity and $\pi$-conjugation. Moreover, polyfurans can be synthesized from renewable resources ${ }^{19}$ and may be biodegradable. ${ }^{20}$ Thus, we believe that the reported poor properties, such as low conductivity, ${ }^{5}$ blue-shifted absorption, ${ }^{11 d}$ and instability, ${ }^{9}$ of polyfurans were due to defects produced during their preparation rather than intrinsic properties of polyfurans.

Here we report the first electrochemically-prepared stable and conducting polyfuran films P1-P7 (Chart 1), which possess all the properties necessary to be considered as conducting polymers suitable for applications in organic electronics. These polymers have several advantages over other conjugated polymers, such as rigidity of the backbone and film smoothness. The use of long oligofurans with solubilizing groups, which have relatively low oxidation potential, as the starting monomers for polymerization was the key factor in obtaining polyfuran with improved properties. The electrochemical and spectroelectrochemical behavior, conductivity, electrochemical stability in air under ambient conditions, as well as the morphology of the prepared polyfuran films were studied and compared with corresponding polythiophene analogues. We also report the development of a synthetic methodology for the preparation of long oligofurans 1-7 substituted with solubilizing groups.

\section{Results}

\section{Synthesis of oligofurans}

Oligomers 1-5 (Schemes 1 and 2) were synthesized by Stille coupling, oligomer 6 (Scheme 3) was synthesized by Kumada coupling, and oligomer 7 (Scheme 3) was obtained by a combination of Kumada and Ullmann couplings of suitable precursors. Synthesis of compounds 1, 10 and 11 was reported previously. ${ }^{14,21}$ Synthesis of oligomers 2, 3, and 4 (Scheme 1) was achieved by Stille coupling of 2,5-dibromo-3-octylfuran (12) with tributyl(furan-2-yl)stannane (9), [2,2'-bifuran]-5-yltributylstannane (10), and $\left[2,2^{\prime}: 5^{\prime}, 2^{\prime \prime}\right.$-terfuran $]-5$-yltributylstannane (11), respectively. The precursor 2,5-dibromo-3-octylfuran (12) was prepared by bromination of 3-octylfuran with $\mathrm{N}$-bromosuccinimide (NBS) with a $68 \%$ yield.

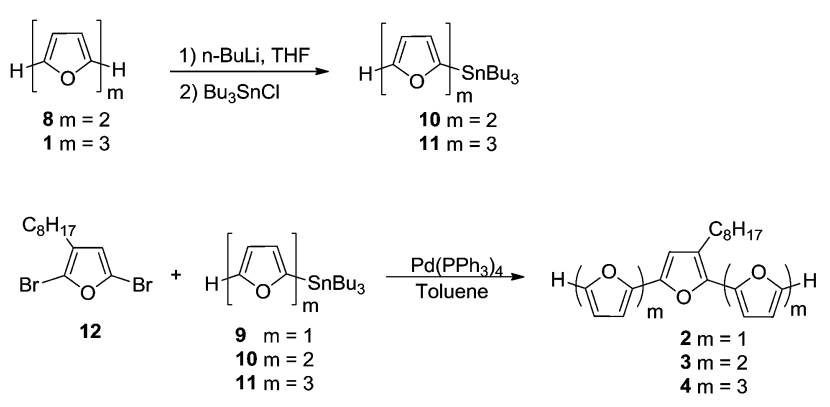

Scheme 1<smiles>Cc1ccc(-c2ccc(-c3ccc(C(F)(F)F)o3)o2)o1</smiles>

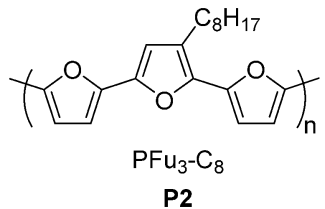<smiles>CCCc1cc(-c2ccc(-c3ccc(C(C)(C)C)o3)o2)oc1-c1ccc(-c2ccc(C(C)(C)C)o2)o1</smiles><smiles>[R6]C(C)(CCCc1cc(-c2ccc(-c3ccc(-c4ccc(C)o4)o3)o2)oc1-c1ccc(-c2ccc(C(=C)C)o2)o1)C(F)(F)F</smiles>

P3

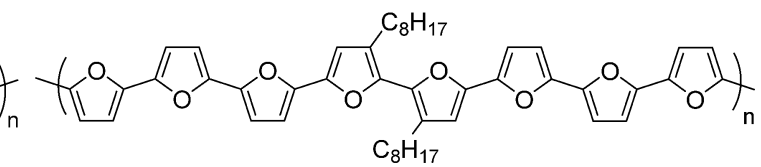

$\mathrm{PFu}_{8}-2 \mathrm{C}_{8}$

P5<smiles>Cc1cc(C)c(-c2oc(-c3cc(C)c(-c4oc(C)cc4C)o3)cc2C)o1</smiles>

Chart 1 Polymers prepared and studied in this work. 

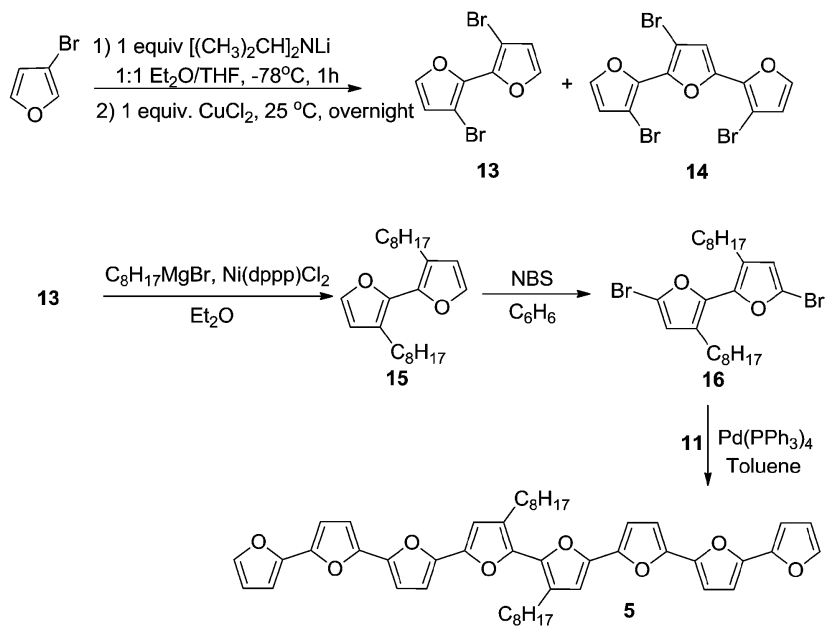

Scheme 2
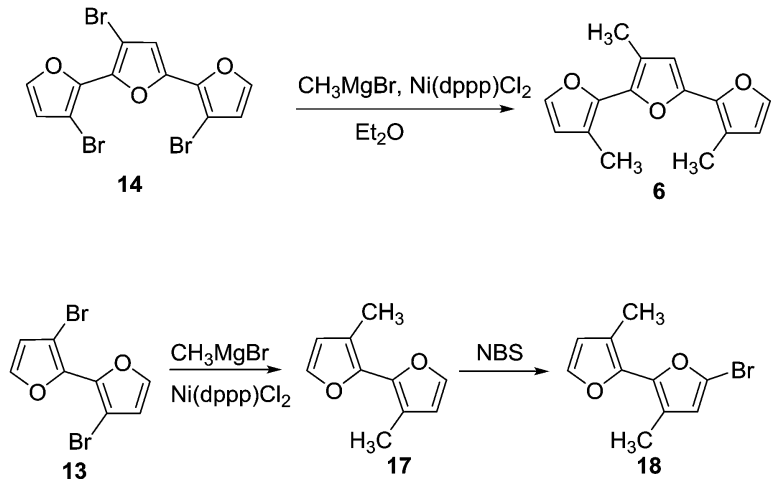<smiles>Cc1ccoc1-c1oc(CS(=O)(=O)[O-])cc1C(F)(F)F</smiles>
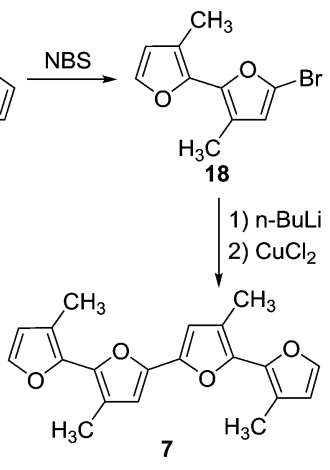

$\mathrm{CH}_{3}$

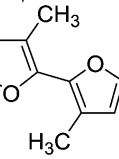

Scheme 3

For the synthesis of octafuran 5 (Scheme 2), dibromo derivative $\mathbf{1 3}$ was prepared using the procedure described in the literature. ${ }^{22}$ Interestingly, during the course of the reaction, terfuran derivative $\mathbf{1 4}$ was also obtained with a $6 \%$ yield. Subsequent reaction of compound $\mathbf{1 3}$ and octylmagnesium bromide with $\mathrm{Ni}(\mathrm{dppp}) \mathrm{Cl}_{2}$ gave $3,3^{\prime}$-dioctyl-2,2'-bifuran (15) with a $74 \%$ yield. Stille coupling of dibromo derivative 16 (obtained from the bromination of 15 using NBS) with $\left[2,2^{\prime}: 5^{\prime}, 2^{\prime \prime}\right.$-terfuran]-5-yltributylstannane (11) yielded dioctylsubstituted octafuran 5 .

Oligomer 2 has the highest octyl chain to furan ratio $(1: 3)$, while oligomer 4 has the lowest octyl chain to furan ratio $(1: 7)$. In order to synthesize polymers having at least a $1: 1$ ratio of alkyl chain to furan ring, bromo groups present in compound $\mathbf{1 4}$ were replaced with alkyl chains. Kumada coupling of $\mathbf{1 4}$ with methylmagnesium bromide gave compound 6 (Scheme 3) with a moderate yield of $51 \%$. The tetramethyl quaterfuran 7 (Scheme 3) was synthesized by lithiation of the monobromo precursor 18 followed by coupling with $\mathrm{CuCl}_{2}$.

\section{Electrochemical polymerization and characterization}

Electropolymerization of furan monomer could be achieved only at high potentials ( $c a .1 .8 \mathrm{~V} v s$. SCE), ${ }^{5,12 a}$ at which point ring opening and irreversible degradation leads to non-conjugated and low quality polyfurans. Thus, the electropolymerization potential needs to be lowered. This is achieved by using oligofurans rather than furan monomer as the repeat units. ${ }^{3 b, 11 b, 23}$ Starting from terfuran, the oxidation potential of oligofurans drastically decreases, and the polymerization process proceeds below $1.0 \mathrm{~V} v s$. SCE. ${ }^{11 b}$ Such low oxidation potentials allowed the preparation of polyfurans reported herein under air at ambient conditions, which can be beneficial for their possible applications.

The electrodeposition of polymers P1-P7 has been performed both potentiodynamically and potentiostatically. The best polyfuran films were obtained using a $0.1-1 \mathrm{mM}$ concentration of the oligomer in an ACN solution containing $0.1 \mathrm{M}$ $\mathrm{TBACF}_{3} \mathrm{SO}_{3}$ as the electrolyte. In general, for potentiodynamic polymerization, the potential was scanned at $50 \mathrm{mV} \mathrm{s}^{-1}$ from $-0.2 \mathrm{~V}$ to $0.8 \mathrm{~V} v s$. $\mathrm{Ag} / \mathrm{AgCl}$-wire and for potentiostatic polymerization, a potential of $0.75 \mathrm{~V} v s$. Ag/AgCl-wire was applied. Further optimization of polymerization conditions is possible for each of the oligomers (see Table S2, ESI+). Smooth electrodeposition and the growth of insoluble, highly adhesive continuous polymeric films were observed on different types of working electrodes (i.e., ITO-coated glass, Pt-disk, Au-coated quartz crystal and IDA). It is worth noting that the electrodes were not modified and specially cleaned as they were in the preparation of smooth polythiophenes. ${ }^{24}$ Representative cyclic voltammograms $(\mathrm{CV})$ for the polymerization of $\mathbf{P 3}\left(\mathrm{PFu}_{5}-\mathrm{C}_{8}\right)$ on ITO electrode, showing stepwise increases in the current over

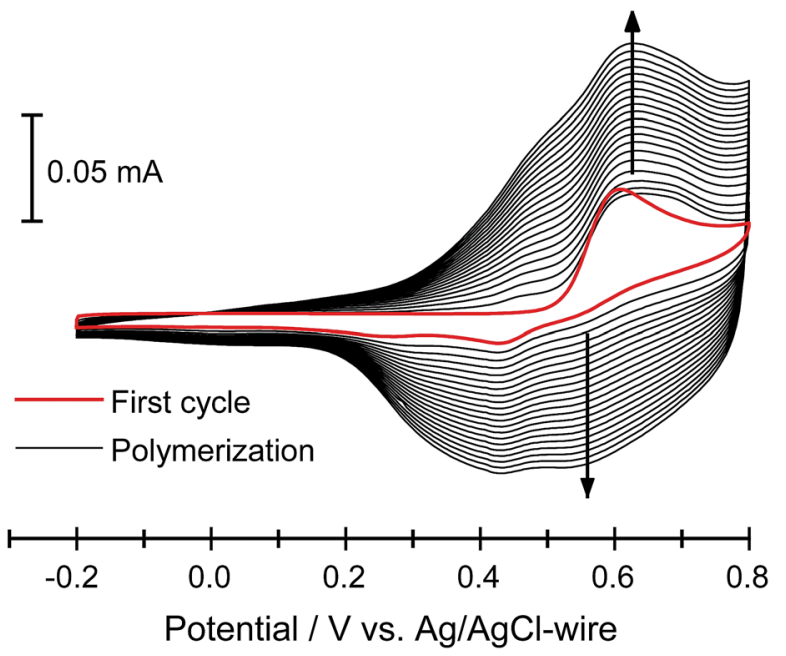

Fig. 1 Electrochemical deposition of $3(0.1 \mathrm{mM})$ in $0.1 \mathrm{M} \mathrm{TBACF}_{3} \mathrm{SO}_{3} /$ $\mathrm{ACN}$ at $50 \mathrm{mV} \mathrm{s}^{-1}$ on an ITO-coated glass slide. 
the course of polymerization, are displayed in Fig. 1 (for other polymers see Fig. S3, ESIt:).

Oxidation peak potentials are poorly resolved for oligomers 1, 2, 4 and 5 (Fig. S3 ). Therefore, the onset potentials for oligomer oxidation $\left(E_{\mathrm{ox}}\right)$, measured from the first $\mathrm{CV}$ curve of the polymerization, were used for comparison between different oligomers (Table 1). As expected, both the introduction of an alkyl group into an oligomer and the elongation of the oligomer decrease the oxidation potential. For example, the $E_{\text {ox }}$ for P1 $\left(\mathrm{PFu}_{3}\right)$ is $0.62 \mathrm{~V}$, whereas for $\mathbf{P 2}\left(\mathrm{PFu}_{3}-\mathrm{C}_{8}\right)$ and $\mathbf{P} \mathbf{3}\left(\mathrm{PFu}_{5}-\mathrm{C}_{8}\right)$, it is $0.51 \mathrm{~V}$ and $0.43 \mathrm{~V}$, respectively. Furthermore, polyfurans are obtained at lower oxidation potentials than polythiophenes, as shown by the oxidation onset potential of terfuran, which is 0.33 $\mathrm{V}$ lower than that of terthiophene.

It is well known that the electrolyte, solvent, oligomer concentration, and method of electropolymerization drastically affect the quality of the resulting polymeric films. ${ }^{1 d, 23,25} \mathrm{We}$ found that $\mathrm{TBACF}_{3} \mathrm{SO}_{3} / \mathrm{ACN}$ electrolyte (see Fig. S4\$ for others) and concentrations of monomers lower than usually used ${ }^{3 b, 11 b}$ produced better polyfurans. Electrolyte anions and solvent could affect the stability of intermediate $\sigma$-dimers, while lower concentrations could reduce $\pi$-dimerization of cation radicals that are produced during electropolymerization. ${ }^{1 d}$

CVs of polyfurans in monomer-free $\mathrm{TBACF}_{3} \mathrm{SO}_{3} / \mathrm{ACN}$ electrolyte showing broad oxidation and reduction peaks (Fig. 2 and S5:), are similar to those of other conducting polymers. ${ }^{1,3 b}$ It is difficult to determine accurate oxidation potentials for polyfurans from the obtained CVs. Nevertheless, oxidation potentials could be estimated from in situ conductivity measurements (see below).

\section{Optical and structural properties}

Spectroelectrochemical studies of the electrochemically produced P1-P7 films on ITO electrodes were performed to evaluate their electronic structure. All prepared polymers exhibited well-defined spectroelectrochemical responses, namely, a reversible and distinct change in the absorption spectrum during the redox processes (doping/dedoping). Fig. 3 shows representative spectroelectrochemical spectra for P1, P2, and $\mathbf{P 6}$ films (for other polymers see Fig. S8 $\$$ ). During polymer oxidation, the absorption peak of the neutral polymer film at around $460 \mathrm{~nm}$ decreases and two peaks at around $750 \mathrm{~nm}$ and $1250 \mathrm{~nm}$ develop. In addition, the isosbestic point is observed at

Table 1 Onset potentials for 1-7 and T3 oligomer oxidation ( $\left.E_{\mathrm{ox}}\right)$

\begin{tabular}{ll}
\hline Oligomer & $E_{\text {ox }}{ }^{a} \mathrm{~V} v$. Ag/AgCl-wire \\
\hline $\mathrm{Fu}_{3}(\mathbf{1})$ & 0.62 \\
$\mathrm{Fu}_{3}-\mathrm{C}_{8}(2)$ & 0.51 \\
$\mathrm{Fu}_{5}-\mathrm{C}_{8}(3)$ & 0.43 \\
$\mathrm{Fu}_{7}-\mathrm{C}_{8}(4)$ & 0.40 \\
$\mathrm{Fu}_{8}-2 \mathrm{C}_{8}(5)$ & 0.37 \\
$\mathrm{Fu}_{3}-3 \mathrm{C}_{1}(\mathbf{6})$ & 0.44 \\
$\mathrm{Fu}_{4}-4 \mathrm{C}_{1}(7)$ & 0.41 \\
$\mathrm{~T}_{3}$ & 0.95
\end{tabular}

${ }^{a}$ For approximate oxidation peak potentials see Table S1.

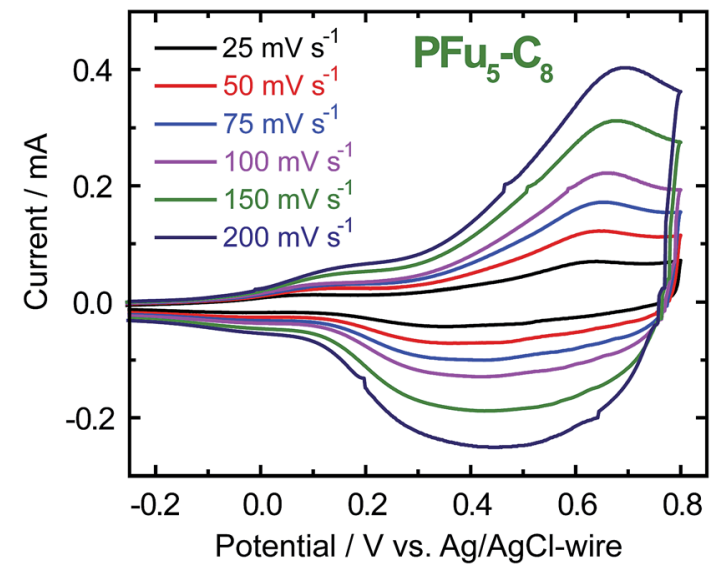

Fig. 2 CV of P3 film on an ITO coated glass electrode in monomerfree $0.1 \mathrm{M} \mathrm{TBACF}_{3} \mathrm{SO}_{3} / \mathrm{ACN}$ electrolyte at different scanning rates.

ca. $530 \mathrm{~nm}$ for P1-P5 and at ca. $550 \mathrm{~nm}$ for P6 and P7. Importantly, the presence of one isosbestic point indicates interconversion between neutral and cation-radical (polaron) states. ${ }^{26}$ Only the $0.7 \mathrm{~V}$ spectral trace of P6 (Fig. 3c) shows beginning of bipolaron formation, which is consistent with the decrease in electrical conductivity (see below).

The measured $\lambda_{\max }$ values of neutral polyfurans are in the range of 456-466 $\mathrm{nm}$ (Table 2). This range is red-shifted compared with most of previously reported values of $<420$ nm. ${ }^{\mathbf{1 0}, \mathbf{1 1 a} \boldsymbol{c}, \boldsymbol{c} \boldsymbol{d}, \mathbf{1 2 b} \boldsymbol{b}}$ This suggests that much longer effective conjugation lengths are obtained in the current work. We note that Kanatzidis et al. reported ${ }^{\mathbf{1 1 b}}$ an absorbtion maximum of $468 \mathrm{~nm}$ for $\mathrm{PFu}_{3}$. However, their spectrum lacks vibronic shoulders, which are observed in all our spectra. We estimate the effective conjugation length in prepared polyfurans to be more than 25 furan units, as can be deduced from extrapolation of the $\lambda_{\max }$ values of $\alpha$-oligofurans (see Fig. S25 $\ddagger$ ).

The optical band gaps of polyfurans estimated from the absorption spectra (Table 2) for unsubstituted P1 and partially alkyl substituted P2-P5 are ca. 2.3 eV. By contrast, for polyfurans P6 and P7 substituted with one methyl group per furan ring, the band gaps are decreased to $c a$. $2.2 \mathrm{eV}$. This observation is consistent with DFT calculations, which showed that alkyl substitution reduces band gaps (Table 2 and S3\$). Moreover, calculations (Table 2) showed that this reduction in band gap occurs because of the increase in the highest occupied crystal orbital (HOCO) energy (i.e. the energy of the valence band), which is partially offset by an increase in the lowest occupied crystal orbital (LUCO) energy (i.e. the energy of the conduction band). Consequently, the oxidation potential of alkylsubstituted polyfurans decreased. The increase of the HOCO energy is consistent with the electron donating property of alkyl groups.

Interestingly, the peak of neutral polyfuran films shows redshifted shoulders (Fig. 3 and S8\%), probably because of the vibronic coupling. ${ }^{27}$ The presence of vibronic coupling may indicate that the polymer backbone is highly rigid, planar and effectively $\pi$-conjugated. We have shown that oligofurans exhibit high rigidity, ${ }^{\mathbf{1 4 2 8}}$ as evident from calculated twisting 
(a)

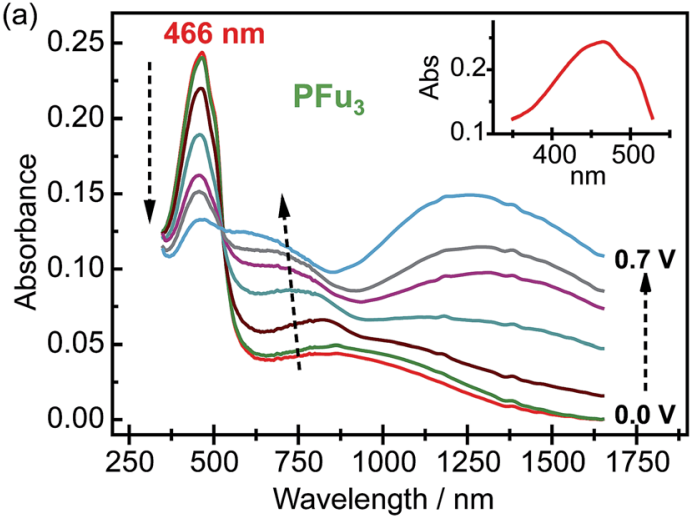

(b)

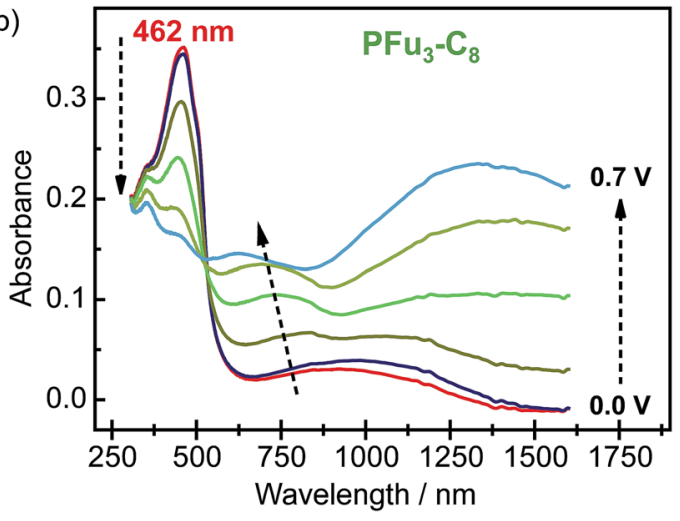

(c)

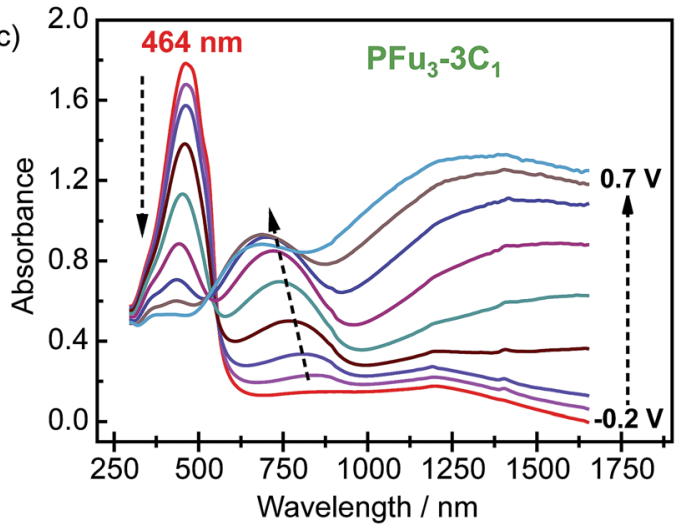

Fig. 3 Spectroelectrochemistry of (a) P1, (b) P2, and (c) P6 on an ITO coated glass electrode in monomer-free $0.1 \mathrm{M} \mathrm{TBACF}_{3} \mathrm{SO}_{3} / \mathrm{ACN}$ electrolyte. Inset (a) shows closer look on the vibronic shoulders of the main absorption peak of $\mathrm{P} 1$ at $0.0 \mathrm{~V}$. Stated potentials are vs. $\mathrm{Ag} / \mathrm{AgCl}-$ wire.

potentials which are higher than for oligothiophenes. Similar computational results have been recently shown for polyfurans. ${ }^{29}$ Consequently, the $\pi$-conjugation and planarity of polyfurans should not be distorted by various substitution of the polyfuran backbone as strongly as it is in the polythiophene family. Indeed, DFT geometry optimization (PBC/B3LYP/631G(d)) of polyfurans P1-P7 shows that the polyfuran backbone remains planar upon alkyl substitution (Fig. 4a and S10 ). In contrast, in polythiophene $\mathrm{PT}_{4}-4 \mathrm{C}_{1}$, which is a thiophene analogue of $\mathbf{P 7}$, the polymer backbone deviates strongly from planarity (Fig. $4 \mathrm{~b}$ ), distorting the $\pi$-conjugation. As a consequence, the calculated band gap for $\mathrm{PT}_{4}-4 \mathrm{C}_{1}$ increases to $2.9 \mathrm{eV}$ from 2.0 eV for planar unsubstituted polythiophene. ${ }^{29,30}$ Whereas measured optical and calculated band gaps for polyfurans P1-P7 are not increased upon alkyl substitution.

\section{IR spectroscopy}

Structural defects in the conjugated backbone of polyfuran can be revealed by IR spectroscopy. ${ }^{32}$ Previously reported polyfurans showed defects, such as ring-opening and $\beta$-coupling, which were observed by stretching vibrational modes of the aliphatic C-H bond $\left(\sim 2900 \mathrm{~cm}^{-1}\right)$, carbonyl $\mathrm{C}=\mathrm{O}$ bond $\left(\sim 1720 \mathrm{~cm}^{-1}\right)$, and $\mathrm{O}-\mathrm{H}$ bond $\left(\sim 3500 \mathrm{~cm}^{-1}\right){ }^{10 b, 11 a-c}$ The measured ATR-FTIR spectra of $\mathbf{P 1}$ and $\mathbf{P 3}$ films on Pt-foil (Fig. 5a and b) show little structural defects for $\mathbf{P 1}$ and almost none for $\mathbf{P} \mathbf{3}$ and are in good agreement with the calculated spectrum of model $\mathrm{Fu}_{20}$ (Fig. 5c, Table S4 and Fig. S12 ) and with previous IR data. ${ }^{10 b, 11 c, 33}$ The IR spectra of $\mathbf{P 1}$ and $\mathbf{P} 3$ are similar, showing the same bands except for the aliphatic $\mathrm{C}-\mathrm{H}$ stretching mode of the octyl substituents at around $2900 \mathrm{~cm}^{-1}$.

\section{In situ conductivity}

The conductivity of conjugated polymers strongly depends on many factors, particularly the method of preparation, the presence of impurities, humidity, and the measurement technique. ${ }^{1 b}$ Owing to their simplicity as well as their ability to obtain a potentiodynamic response, in situ conductivity measurements using an interdigitated array (IDA) microelectrode $\mathrm{e}^{34}$ or two-band electrode $\mathrm{e}^{35}$ have found wide use. ${ }^{36}$ However, obtaining the absolute value of polymer film conductivity is not straightforward because it depends on many factors that are hard to define, such as nontrivial geometrical factor of the electrode, non-linear dependence of the conductance on film thickness, and undefined contact resistances. Thus, we report conductance values in comparison to that of poly(terthiophene) ( $\left.\mathrm{PT}_{3}\right)$, which was electrochemically prepared and measured under the same setup. Additionally, we compare the conductance values of our polyfurans to those of drop-cast commercial poly(3,4-ethylenedioxythiophene) poly(styrenesulfonate) (PEDOT:PSS) film on the same type of electrode. The conductivity of electrochemically prepared $\mathrm{PT}_{3}$ film $^{7 a}$ and that obtained from commercial PEDOT:PSS ${ }^{37}$ is estimated to be on the order of $1 \mathrm{~S} \mathrm{~cm}^{-1}$.

Fig. 6 shows simultaneous measurements of $\mathrm{CV}$ and conductance of P1-P4, P6 and P7 films. All obtained polyfurans show maximum conductances comparable to those of $\mathrm{PT}_{3}$ and PEDOT:PSS films (Table 3, Fig. S15 $\$$ ). Thus electrical conductivities of doped polyfurans are in the order of $1 \mathrm{~S} \mathrm{~cm}^{-1}$. This conductivity is much higher than most published values, which range from $10^{-2}$ to $10^{-5} \mathrm{~S} \mathrm{~cm}^{-1}$.

Each polymer undergoes transition to conductive state at different potentials (Fig. 6 and S15 ). We used the potential at half-maximal conductance (for the forward scan) ( $\left.E_{\mathrm{hc}}\right)$ for comparison between polymers. As evident from Table $3, E_{\mathrm{hc}}$ depends on the degree of alkyl substitution, i.e., $E_{\mathrm{hc}}$ decreases with increasing degree of alkyl substitution (Table 3). For example, the value of $E_{\mathrm{hc}}$ for fully methylated polyfuran $\mathbf{P 6}$ is 0.39 $\mathrm{V}$ is lower than that of the unsubstituted P1. Since, the transition to conductive state is associated with the oxidation of a 
Table 2 Experimental and calculated electronic and optical properties for neutral P1-P7

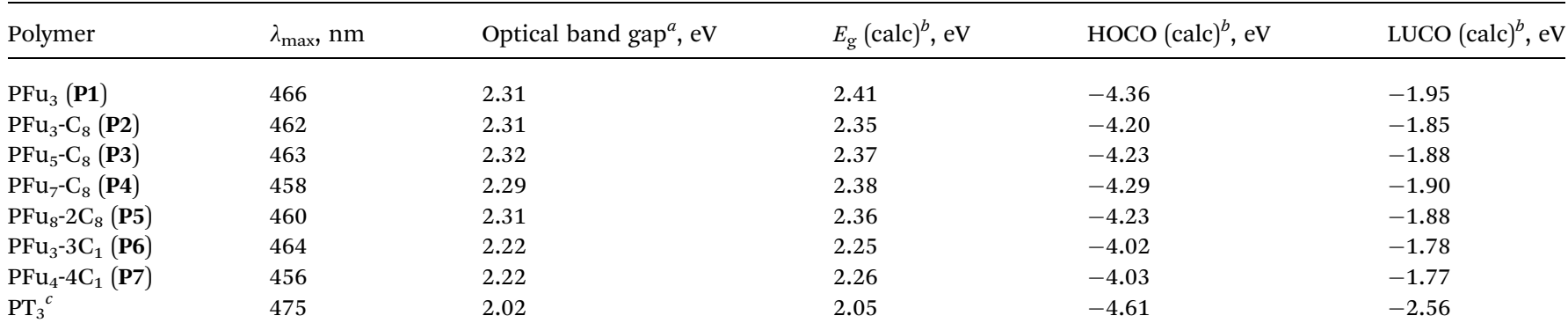

${ }^{a}$ The optical band gaps were obtained from the extrapolation of the linear part of the $(\alpha h \nu)^{2} v s$. $h \nu$ plot to $(\alpha h \nu)^{2}=0$, where $\alpha$ is the absorption coefficient. ${ }^{b}$ Calculated using the $\mathrm{PBC} / \mathrm{B} 3 \mathrm{LYP} / 6-31 \mathrm{G}(\mathrm{d})$ level. ${ }^{c}$ For comparison, $\mathrm{PT}_{3}$ was prepared and measured in this work at same conditions as polyfurans.

(a)

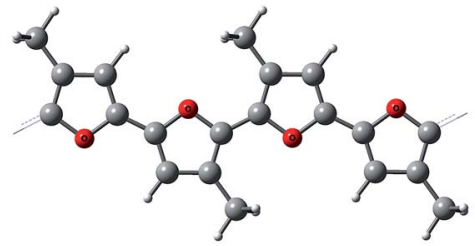

(b)
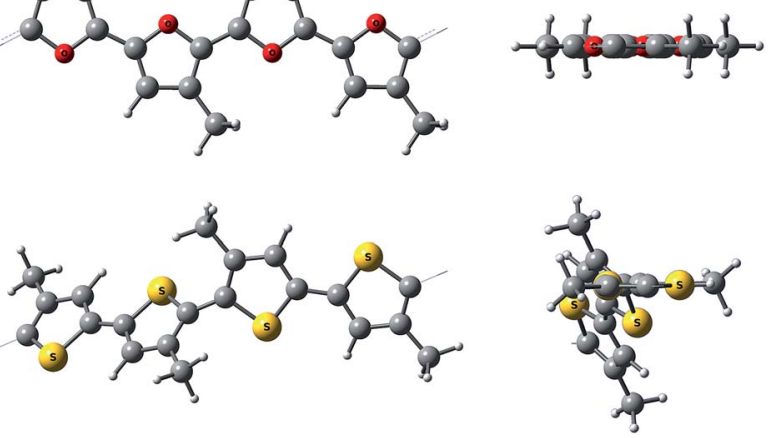

Fig. 4 Calculated (PBC/B3LYP/6-31G(d)) geometry of (a) P7 and (b) polythiophene analog of $\mathrm{P} 7, \mathrm{PT}_{4}-4 \mathrm{C}_{1}$. A side view and a view along the polymer backbone.

conjugated polymer, we can conclude that the oxidation potential of polyfurans is also decreased by alkyl substitution. This is in the agreement with DFT calculations, which show increase in energy of the HOCO as the degree of alkyl substitution increases (Table 2 and $\mathrm{S} 3$ ). Furthermore, for polyfurans, the $E_{\mathrm{hc}}$ potentials are lower than that of $\mathrm{PT}_{3}$ but higher than that of PEDOT, which is consistent with the higher oxidation potential of $\mathrm{PT}_{3}$ (ref. 38) and the lower oxidation potential of PEDOT. ${ }^{39}$

We observe that the conductivity of fully methylated polyfurans P6 and P7 reaches maximum at $0.5 \mathrm{~V}$ and $0.6 \mathrm{~V}$, respectively, and decreases at higher potentials. This observation may suggest that the charge carriers are polarons. Upon further electrochemical oxidation, their conductivity decreases (reversibly) as bipolarons are formed. However, this behavior is not observed in polyfurans P1-P4 due to degradation of the polyfuran films at potentials above $0.8 \mathrm{~V}$, where their conductivity decreases irreversibly.

\section{Electrochemical stability}

The electrochemical stability of conducting polymers is of utmost importance for their use in electrochemical systems, such as batteries, electrocatalytic materials, sensor devices, and other electronic components. ${ }^{40}$ Electrochemical degradation of (a)

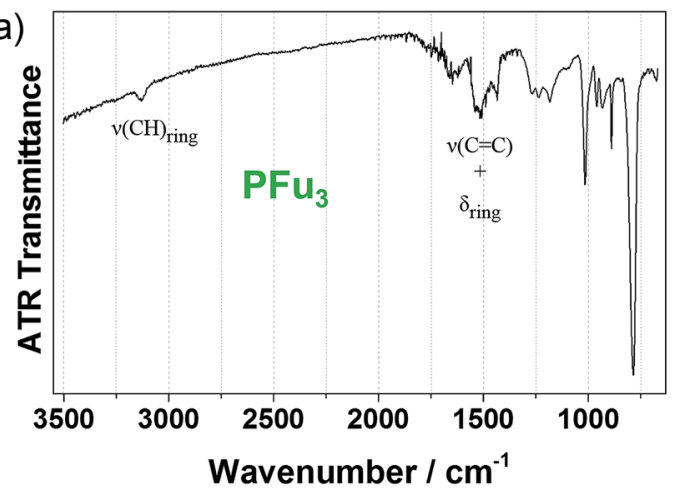

(b)

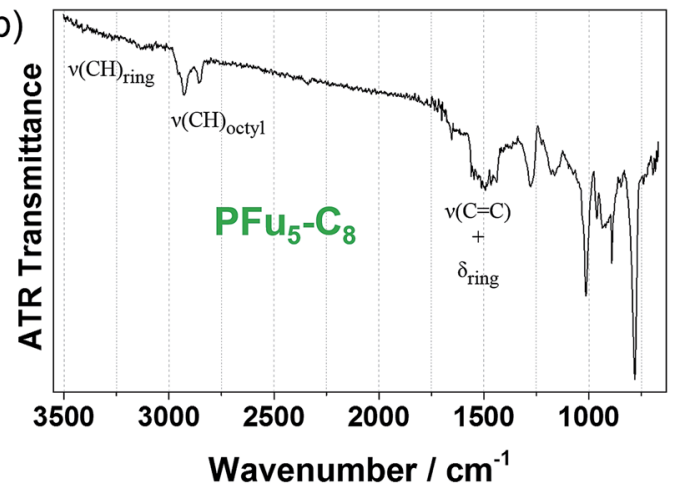

(c)

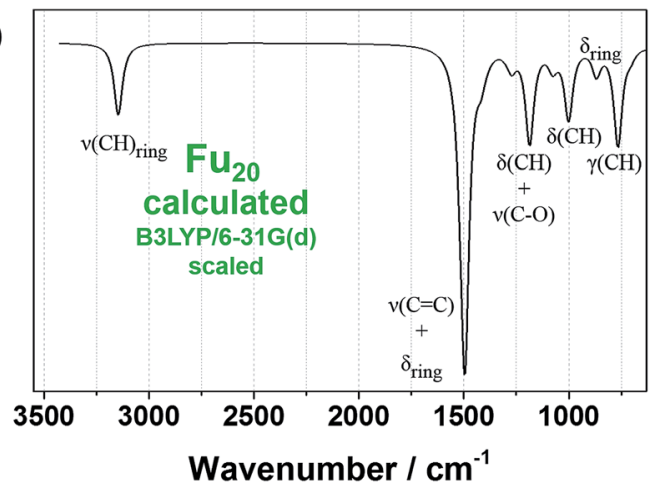

Fig. 5 Experimental FTIR-ATR spectra: (a) of P1 and (b) of P3 films electrodeposited on platinum foil. (c) DFT B3LYP/6-31G(d) calculated IR spectrum of $\mathrm{Fu}_{20}$ (frequencies were scaled by 0.96 (ref. 31)). 

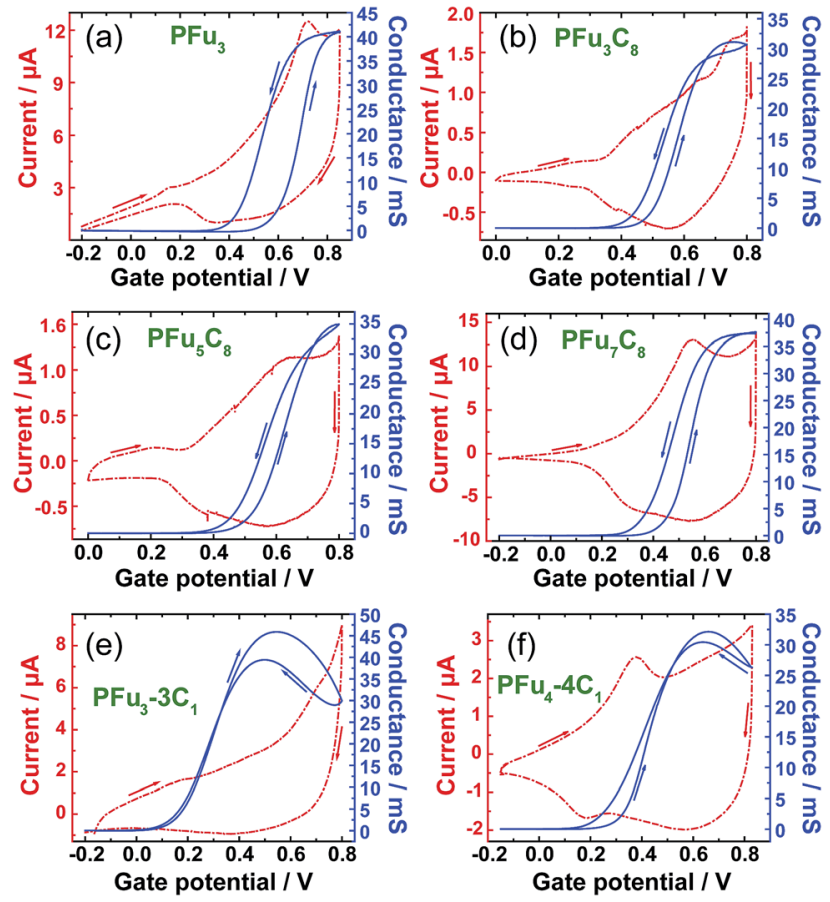

Fig. 6 Cyclic voltammograms (dashed line) and in situ conductance measurements (solid line) for: (a) P1, (b) P2, (c) P3, (d) P4, (e) P6 and (f) $\mathrm{P} 7$ in monomer-free $\mathrm{TBACF}_{3} \mathrm{SO}_{3} / \mathrm{ACN}$ using a $10 \mu \mathrm{m}$ interdigitated array gold microelectrode. Sweep rates are $10 \mathrm{mV} \mathrm{s}^{-1}$ for cyclic voltammograms with a $10 \mathrm{mV}$ probe potential for conductivity measurements. Stated potentials are vs. Ag/AgCl-wire.

Table 3 Conductance and half-maximal conductance potential $\left(E_{\mathrm{hc}}\right)$ for forward scan in P1-P4, P6, P7, PT 3 and PEDOT

\begin{tabular}{lcl}
\hline Polymer & $\begin{array}{l}\text { Conductance } \\
\text { (max), mS }\end{array}$ & $E_{\mathrm{hc}}^{a}, \mathrm{~V}$ \\
\hline $\mathrm{PFu}_{3}(\mathbf{P 1})$ & 43 & 0.69 \\
$\mathrm{PFu}_{3}-\mathrm{C}_{8}(\mathbf{P 2})$ & 32 & 0.58 \\
$\mathrm{PFu}_{5}-\mathrm{C}_{8}(\mathbf{P 3})$ & 38 & 0.62 \\
$\mathrm{PFu}_{7}-\mathrm{C}_{8}(\mathbf{P 4})$ & 37 & 0.55 \\
$\mathrm{PFu}_{3}-3 \mathrm{C}_{1}(\mathbf{P 6})$ & 46 & 0.30 \\
$\mathrm{PFu}_{4}-4 \mathrm{C}_{1}(\mathbf{P} 7)$ & 32 & 0.44 \\
$\mathrm{PT}_{3}$ & 42 & 0.87 \\
$\mathrm{PEDOT}_{\text {PEDOT:PSS }}$ & $>72^{b}$ & -0.21 \\
& 50 & -
\end{tabular}

${ }^{a}$ Half-maximal conductance potential ( $v s$. Ag/AgCl-wire) for the forward scan. ${ }^{b}$ Limited by the resistance of the IDA electrode contacts (Fig. S15). ${ }^{c}$ Drop-cast film.

conductive polymers, such as polypyrrole, polythiophene, and polyaniline, has been studied extensively ${ }^{40}$ However, very little has been reported on the electrochemical degradation of polyfuran. ${ }^{10 b, 11 c}$

(a) Redox current stability. The electrochemical cyclability of the polyfurans was tested using cyclic voltammetry between -0.3 to $0.7 \mathrm{~V} v s$. Ag/AgCl-wire in a monomer-free $\mathrm{TBACF}_{3} \mathrm{SO}_{3} /$ ACN electrolyte solution for up to 2000 cycles in the air under ambient conditions (Fig. 7). Polyfurans P1 and P3 show reasonable electrochemical stability, with oxidation current remaining at $c a .50 \%$ after 1000 cycles. This is considerably better than the values reported for polyfurans retention of redox activity (40-50\% over 100 cycles). ${ }^{10 b, 11 c}$ In order to properly compare the stability of polyfurans with that of $\mathrm{PT}_{3}$, the potential scan window was shifted by $0.2 \mathrm{~V}$ towards higher potentials. The reasoning for this stems from the fact that $\mathrm{PT}_{3}$ has a higher oxidation potential. ${ }^{3 b, 41}$ Under these conditions, polyfurans showed slightly better stability than $\mathrm{PT}_{3}$ (Fig. 7c), because $\mathrm{PT}_{3}$ undergoes faster degradation due to higher applied potential that is required to induce its conductivity. Furthermore, as shown in Fig. S13, the addition of $1 \% \mathrm{v} / \mathrm{v}$ water to the electrolyte solution had a small effect on the electrochemical stability of polyfuran P3. As expected, the electrochemical stability upon cycling over $0.0-0.5 \mathrm{~V}$ was much higher (Fig. S14 ). P1 and $\mathbf{P 3}$ show only a $25 \%$ reduction in oxidation current after 10000 cycles (Fig. S14a and c\$).
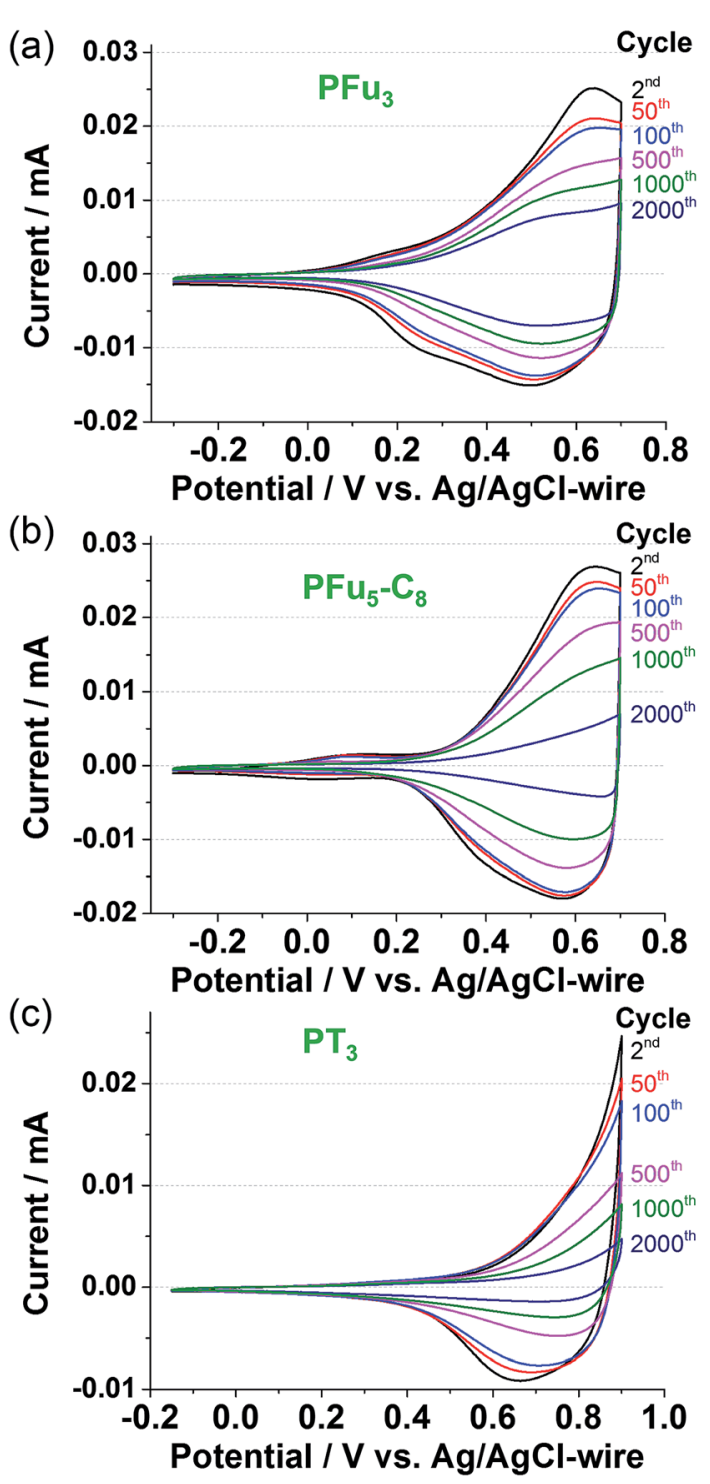

Fig. 7 Long term CV at $100 \mathrm{mV} \mathrm{s}^{-1}$ of polymer films: (a) P1, (b) P3, and (c) $\mathrm{PT}_{3}$ on Pt-disk electrode in monomer-free $0.1 \mathrm{M} \mathrm{TBACF}_{3} \mathrm{SO}_{3} / \mathrm{ACN}$ electrolyte. 
(b) Optical switching and stability. Optical switching was measured for doped P1, P3, and $\mathrm{PT}_{3}$ at the maximum absorption peak wavelength in the NIR region (see spectroelectrochemistry above), within which the degraded and nonelectroactive polyfurans show no absorbance. The stability of optical switching was evaluated by applying repetitive potential pulses (10 s length) of $0.0 \mathrm{~V}$ and $0.7 \mathrm{~V}$ for polyfurans, and $0.0 \mathrm{~V}$ and $0.9 \mathrm{~V}$ for $\mathrm{PT}_{3}$ for prolonged time (2 h) (Fig. 8). For complete doping and achievement of maximal NIR absorbance, higher potential was needed for $\mathrm{PT}_{3}$.

The degraded optical activities (i.e., difference in transmittance of undoped and doped state) obtained after $120 \mathrm{~min}$ of cycling (for a total of 360 cycles) were found to be $39 \%, 45 \%$, and $51 \%$ for P1, P3 and $\mathrm{PT}_{3}$ of the starting activity, respectively. Thus, polyfurans P1 and P3 showed only slightly lower stabilities compared with $\mathrm{PT}_{3}$, but are much better than that reported for a PFu/PEDOT device. ${ }^{\mathbf{1 0}}$

(c) Stability in conductive state. The stability of the conductive state of the $\mathbf{P 1}, \mathbf{P} 3$ and $\mathrm{PT}_{3}$, was tested on an IDA electrode by applying a constant potential for a prolonged time (up to $18 \mathrm{~h}$ ) in air under ambient conditions (Fig. 9). A potential of $0.7 \mathrm{~V}$ was used for polyfurans $\mathbf{P 1}$ and P3. For polythiophene $\mathrm{PT}_{3}$, a potential of $0.9 \mathrm{~V}$ was used. These potentials correspond to slightly lower potential at which the polymers exhibit maximum conductance (Fig. 6).

As shown in Fig. 9, polyfurans P1 and P3 show much higher stabilities toward continuous potential application than $\mathrm{PT}_{3}$, whose lower stability is likely due to the high potential $(0.9 \mathrm{~V})$ needed for oxidation (doping), which in turn, is expected to break the conjugation of the backbone via side reactions. ${ }^{42}$
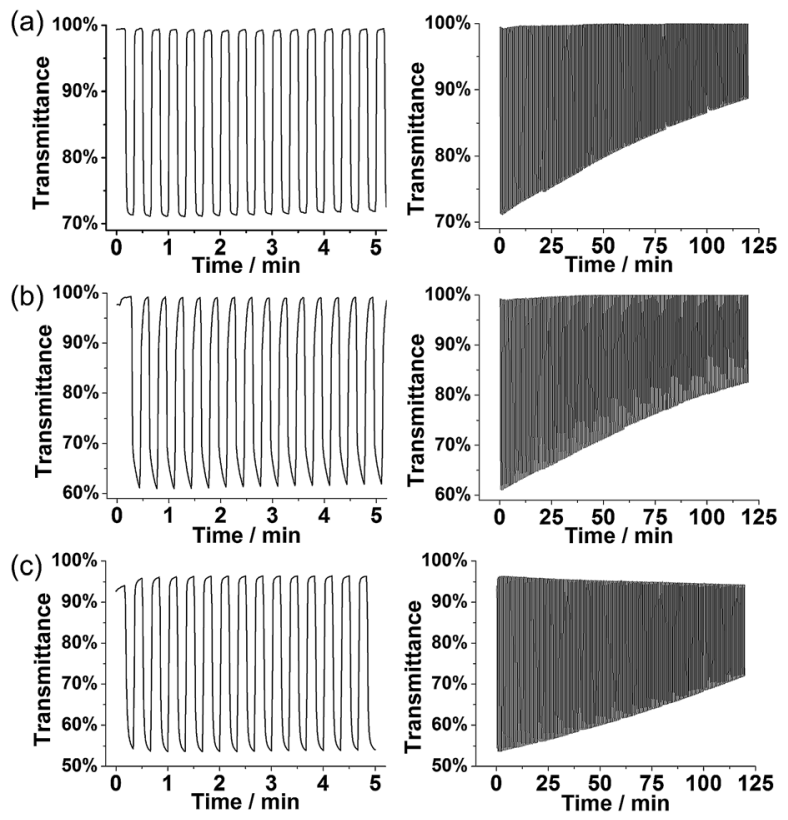

Fig. 8 Optical switching and stability of polymer films: (a) P1 at 1250 $\mathrm{nm}$, (b) P3 at $1350 \mathrm{~nm}$, and (c) $\mathrm{PT}_{3}$ at $1275 \mathrm{~nm}$ on ITO coated glass electrodes in monomer-free $0.1 \mathrm{M} \mathrm{TBACF} \mathrm{SO}_{3} / \mathrm{ACN}$ electrolyte. Voltage pulses of $0.0 \mathrm{~V}$ and $0.7 \mathrm{~V}$ (for P1 and P3) and of $0.0 \mathrm{~V}$ and $0.9 \mathrm{~V}$ (for $\mathrm{PT}_{3}$ ) were applied for $10 \mathrm{~s}$.

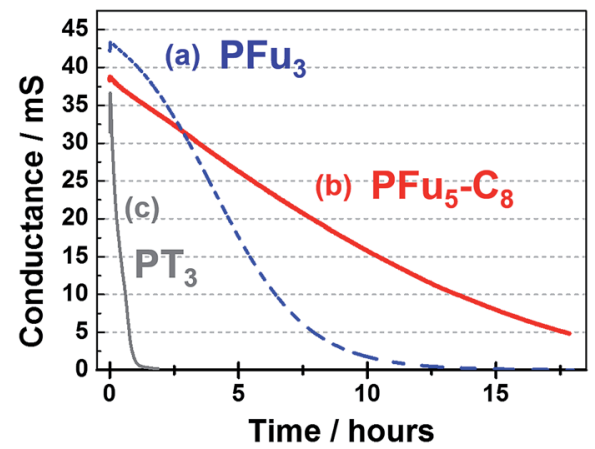

Fig. 9 Stability of the conductive state of polymer films: (a) P1 at 0.7 V, (b) $\mathrm{P} 3$ at $0.7 \mathrm{~V}$, and (c) $\mathrm{PT}_{3}$ at $0.9 \mathrm{~V}$ on an IDA electrode in monomerfree $0.1 \mathrm{M} \mathrm{TBACF}_{3} \mathrm{SO}_{3} / \mathrm{ACN}$ electrolyte.

Thus, the lower potential required for doping the polyfurans is advantageous because it minimizes the occurrence of backbone degradation under ambient conditions.

\section{Morphology}

Polymer morphology has a significant effect on polymer chargetransport properties. ${ }^{1 b}$ Controlled film thickness, surface smoothness, and uniformity are important considerations for application of conductive polymers in thin film devices (where high surface area is not required, such as sensing), including photovoltaic cells and OFETs. Electrochemical deposition has some advantages over solution processing of conjugated polymers. It combines polymer formation and deposition in onestep and bypasses the need for polymer isolation and purification. As such, it has found use in fabrication of organic electronic devices. ${ }^{43}$ However, it is difficult to obtain smooth and homogeneous thin films by electropolymerization, necessitating the optimization of electrodeposition. ${ }^{\mathbf{1 d}}$ For example, the root mean square roughness $\left(r_{\mathrm{rms}}\right)$ of $\mathrm{PT}_{3}$ on ITO is $173 \mathrm{~nm}$ (Fig. S18 ) and PT on ITO is $25-174 \mathrm{~nm}^{24}$ To the best of our knowledge, the lowest $r_{\text {rms }}$ value obtained for electrodeposited PEDOT films in organic media is $46 \mathrm{~nm}^{25 c}$ Smooth polythiophene films were obtained after modification of the working electrode, ${ }^{\mathbf{2 4 , 4 4}}$ while smooth electrodeposited PEDOT films were obtained from microemulsions in aqueous solution. ${ }^{45}$ The polymer precursor approach (i.e., use of inert polymer with pendant electroactive monomer units) was proposed to obtain thin films of less than $100 \mathrm{~nm}$ with controllable thickness. ${ }^{46}$ The drawback of this method, however, is that prior polymer synthesis is necessary.

As can be seen in Fig. 10 showing SEM and AFM images of representative example of $\mathbf{P} 3$ on HOPG electrode (for the additional images of polyfurans on different electrodes see ESI $\$$ ), the prepared polyfuran films show excellent surface smoothness and complete coverage of all working electrodes used. In contrast, polythiophene exhibits separate islands of film and areas of bare electrode surface (see Fig. S17t for similarly prepared $\left.\mathrm{PT}_{3}\right) .{ }^{47}$ Additionally, polyfuran films have high adhesion to the electrode surface and are not easily detached. For example, they cannot be pulled off by sticking adhesive tape to 

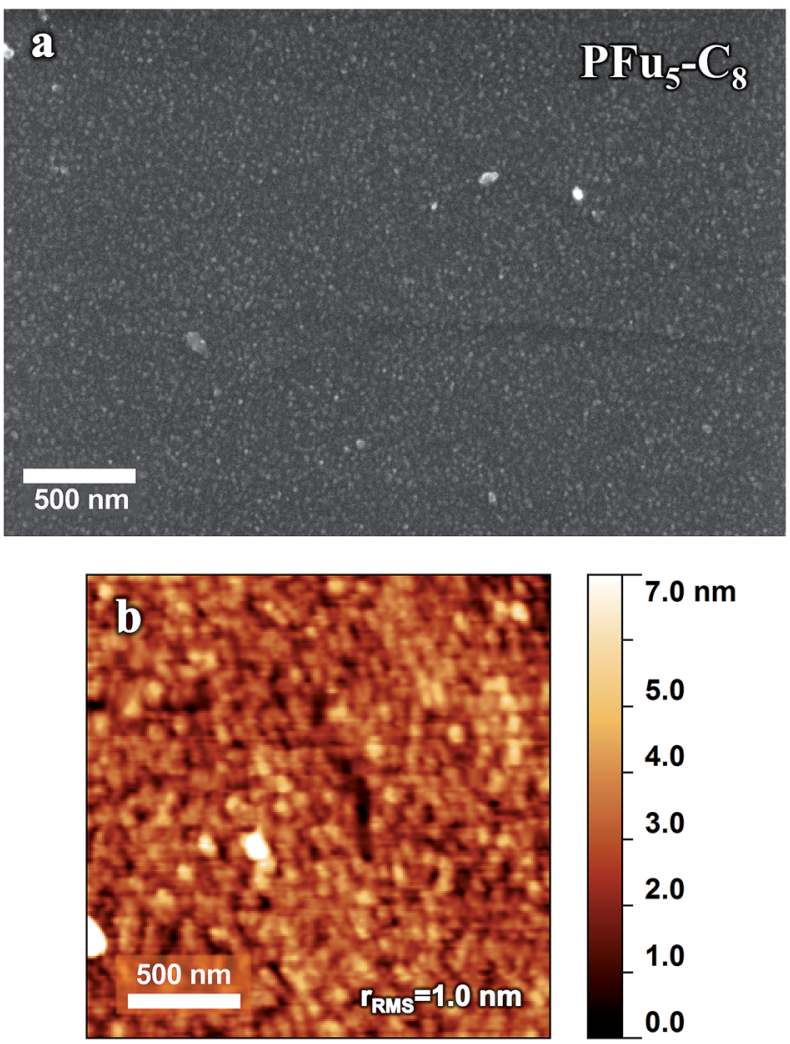

Fig. 10 (a) SEM and (b) AFM images of P3 film prepared on a HOPG electrode by $\mathrm{CV}$ polymerization using potential scanning from $-0.2 \mathrm{~V}$ to $0.78 \mathrm{~V}$ for 1 cycle of $0.2 \mathrm{mM}$ of monomer 3 in $0.1 \mathrm{M} \mathrm{TBACF}_{3} \mathrm{SO}_{3} /$ ACN electrolyte. Film thickness is $10 \mathrm{~nm}$.

the electrode, as in case of poly(3-methylthiophene) films. ${ }^{48}$ Additionally, films were found to be completely insoluble in organic solvents, such as THF and toluene.

The thickness of prepared polyfuran films can be easily controlled and tailored for the specific application. For instance, the film thickness of $\mathbf{P 3}$ linearly depends on the number of $\mathrm{CV}$ cycles used in the polymerization (Fig. 11). The thickness of $10 \mathrm{~nm}$ on HOPG electrode was obtained after 1 cycle (Fig. 10), $45 \mathrm{~nm}$ after 5 cycles (Fig. S19 ) and $90 \mathrm{~nm}$ after 10 cycles (Fig. S20 ). The films show full coverage of electrodes with very smooth and homogeneous morphology. Although the $r_{\text {rms }}$ value for the $10 \mathrm{~nm}$ thick film was only $1 \mathrm{~nm}$, it increased with film growth, as evidenced by the $r_{\text {rms }}$ values of $3.5 \mathrm{~nm}$ and 5 $\mathrm{nm}$ for 45 and $90 \mathrm{~nm}$ thick films, respectively (Fig. S20 ). For polyfuran films with thickness above $50 \mathrm{~nm}$, formation of globular structures on the top of smooth film is observed on both HOPG and ITO electrodes (see Fig. S20-S22\$). Polyfuran film roughness on an ITO electrode (Fig. S21-S22 than on HOPG and is due to inherent higher roughness of the electrode (i.e., $r_{\mathrm{rms}}=4.6 \mathrm{~nm}$ for bare ITO, Fig. S23 ).

\section{Discussion}

Overall, we have shown that by careful selection of starting oligomers and electropolymerization conditions (i.e.,

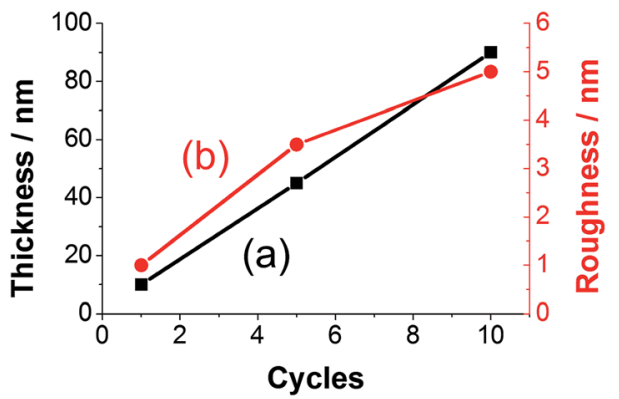

Fig. 11 Dependence of (a) thickness and (b) roughness on number of CV cycles used for polymerization of P3 on HOPG electrode.

electrochemical method, monomer concentration, electrolyte and solvent), polyfurans of good quality are obtained. By lowering the polymerization potential using long oligofurans as the starting monomers, the polyfurans could be prepared in open air under ambient conditions.

The measured high conductivity on the order of $1 \mathrm{~S} \mathrm{~cm}^{-1}$ for doped polyfuran films may be attributed to better quality of the prepared polyfurans when compared with previous reports. ${ }^{5}$ This increased quality is manifested in the longer effective conjugation lengths (estimated to be above 25 furan units based on oligomer data, Fig. S25 revealed by absorption spectra of the reduced (dedoped) polyfuran films, which show considerable red-shifted (456-466 $\mathrm{nm}$ ) absorption maxima compared to most reported polyfurans. ${ }^{11 a, c, d, 12 b}$ Additionally, IR spectroscopy showed almost no structural defects, including ring opening and $\beta$-coupling in the backbone. Moreover, absorption spectra of the neutral polyfurans show vibronic coupling, indicative of well-ordered, planar, and rigid polymers. Although similar vibronic coupling is also observed in highly conductive samples of $\mathrm{PT}^{49}$ and PEDOT, ${ }^{27 b}$ they were not previously observed in electrochemically prepared polyfurans. Furthermore, the measured conductivity of polyfurans is comparable to the conductivity of electrochemically prepared poly(oligothiophene)s. ${ }^{7 a}$ Thus, we are convinced that the previously reported low conductivities ${ }^{5}$ are due to preparation problems, and are not an intrinsic property of polyfurans.

We have studied the effect of alkyl substitution on the properties of polyfurans. DFT calculations predict reductions of the band gaps, as well as oxidation potentials of polyfurans, with increasing alkyl substitution ratio (see Table S3 compared to P1, we experimentally observe a reduction of around $0.08 \mathrm{eV}$ (Table 2) in optical band gaps in fully methylated polyfurans P6 and P7. Although we cannot reliably measure the oxidation potentials from cyclic voltammetry, we do qualitatively observe that the onset of the broad oxidation peak is shifted to lower potentials for P6 and P7. Another estimation of oxidation potentials can be obtained from the potential at half-maximum conductance $E_{\mathrm{hc}}$, which is significantly decreased upon alkyl substitution (e.g., $E_{\mathrm{hc}}=0.69 \mathrm{~V} v s$. $\mathrm{Ag} / \mathrm{AgCl}$-wire for $\mathrm{PFu}_{3}(\mathbf{P 1})$ and $E_{\mathrm{hc}}=0.30 \mathrm{~V}$ for $\mathrm{PFu}_{3}-3 \mathrm{C}_{1}(\mathbf{P 6})$ ). Furthermore, $E_{\mathrm{hc}}$ for polyfurans is lower than that of $\mathrm{PT}_{3}\left(E_{\mathrm{hc}}=\right.$ $0.87 \mathrm{~V})$. Therefore, when compared to polythiophenes, a lower oxidation potential of polyfurans serves as an advantage. The 
lower doping potential minimizes the occurrence of the destructive side reactions (e.g., with water and oxygen). Moreover, oligofurans show lower oxidation potential compared to oligothiophenes, as evidenced by the onset potentials for oligomer oxidation ( $0.62 \mathrm{~V}$ for terfuran and $0.95 \mathrm{~V}$ for terthiophene).

As shown by DFT calculations ${ }^{29}$ and absorption spectra (Fig. 4 and S11\%), polyfurans have the further advantage of being more rigid than polythiophenes. High rigidity of polyfurans is also consistent with the experimental observation that regioirregular methylated polyfurans $\mathbf{P 6}$ and $\mathbf{P 7}$ show lower band gaps and oxidation potentials. This is advantageous for future development of furan-based polymers, where regioregular arrangement of different functional groups (otherwise needed in the case of polythiophenes to keep the efficient $\pi$ conjugation, e.g., rrP3HT) $)^{50}$ is no longer mandatory.

We have carefully studied the stability of electrochemical, optical, and conductive properties of polyfurans in open air under ambient conditions. The stability of the redox activity and conductivity over time showed that polyfurans are actually more stable than polythiophene $\mathrm{PT}_{3}$ under similar conditions. This stability is attributed to lower potential needed for doping of polyfurans. The optical switching stability of polyfurans is found to be comparable with that of $\mathrm{PT}_{3}$, and it is much better than the previously reported stability of the optical switching of a PFu/PEDOT device at $415 \mathrm{~nm}$. Previous studies showing optical switching degradation after only $90 \mathrm{~s}$ then is likely attributable to the polyfuran's poor quality, as suggested by the low absorption maximum $\left(\lambda_{\max }=420\right){ }^{10 c}$ Therefore, we believe that the earlier reported instabilities of polyfurans are also due to problems in their preparation.

We have identified two phases of the polyfuran film growth. Initially (up to $c a .50 \mathrm{~nm}$ thickness), we observe a smooth thin film covering the whole electrode surface is formed. As the film continues to grow, globular bumps and aggregates are observed on top of the smooth film surface. As a result, the roughness of the surface increases. For instance, in P3 on HOPG, the $r_{\text {rms }}$ value was $c a .5 \mathrm{~nm}$ for the underlying film and $c a .17 \mathrm{~nm}$ for the full scanned area (Fig. S20 ). The formation of the structures on top of homogenous film is consistent with electrochemical polymerization where a new polymer forms at surface points with a higher conductivity.

It is worth noting that prepared polyfuran films have lower roughness than most other electrochemically-prepared films under similar conditions, ${ }^{24,25 c, 44-46}$ i.e., in organic media electrolyte, in ambient environment, without electrode surface modifications and extensive electrode cleaning. This is certainly an advantage for technological applications of polyfurans.

\section{Conclusion}

Using long oligofurans as precursors, we were able to obtain and thoroughly characterize polyfuran films with different alkyl substitutions that exhibit high stability, are spectroelectrochemically active, show good conductivity in the open air under ambient conditions, and have smooth morphology. These properties are considerably improved from any other known polyfuran prepared electrochemically. Additionally, we showed that polyfurans exhibit high rigidity, which allows many different substituents to be introduced without distorting the planarity and conjugation of the polyfuran backbone. We showed that regioirregular alkyl-substituted polyfurans do not lose their conjugation, and moreover exhibit reduced band gaps.

Polymerization of oligofurans using considerable lower potential than parent furan allowed us to obtain stable polyfurans with very good properties. This is in contrast to the previous belief that polyfurans are intrinsically unstable and possess low conductivity. We believe that this work will establish polyfurans as a fundamental series of conductive polymers with important properties, opening up future applications for polyfurans as conductive polymers.

\section{Acknowledgements}

We thank the Kamin program administrated by the Ministry of Trade and Industry, the Leona M. and Harry B. Helmsley Charitable Trust, and the Helen and Martin Kimmel Center for Molecular Design for financial support.

\section{Notes and references}

1 (a) H. S. Nalwa, Handbook of organic conductive molecules and polymers, Wiley, Chichester, 1997; (b) T. A. Skotheim and J. R. Reynolds, Handbook of conducting polymers, CRC Press, Boca Raton, FL, 2007; (c) G. Inzelt, Conducting Polymers: a New Era in Electrochemistry, Springer, New York, 2008; (d) J. Heinze, B. A. Frontana-Uribe and S. Ludwigs, Chem. Rev., 2010, 110, 4724.

2 (a) R. McNeill, R. Siudak, J. Wardlaw and D. Weiss, Aust. J. Chem., 1963, 16, 1056; (b) S. J. Higgins, Chem. Soc. Rev., 1997, 26, 247; (c) S. Sadki, P. Schottland, N. Brodie and G. Sabouraud, Chem. Soc. Rev., 2000, 29, 283; (d) K. T. Song, S. H. Cho and J. Y. Lee, in Conjugated Polymers, CRC Press, 3rd edn, 2007, ch. 8, p. 87.

3 (a) I. F. Perepichka and D. F. Perepichka, Handbook of thiophene-based materials: applications in organic electronics and photonics, Wiley, Chichester, West Sussex, England, 2009; (b) J. Roncali, Chem. Rev., 1992, 92, 711; (c) A. Mishra, C.-Q. Ma and P. Bäuerle, Chem. Rev., 2009, 109, 1141.

4 (a) A. Patra, Y. H. Wijsboom, S. S. Zade, M. Li, Y. Sheynin, G. Leitus and M. Bendikov, J. Am. Chem. Soc., 2008, 130, 6734; (b) M. Heeney, W. Zhang, D. J. Crouch, M. L. Chabinyc, S. Gordeyev, R. Hamilton, S. J. Higgins, I. McCulloch, P. J. Skabara, D. Sparrowe and S. Tierney, Chem. Commun., 2007, 5061; (c) A. Patra and M. Bendikov, J. Mater. Chem., 2010, 20, 422; (d) L. Li, J. Hollinger, A. A. Jahnke, S. Petrov and D. S. Seferos, Chem. Sci., 2011, 2, 2306.

5 M. J. González-Tejera, E. Sánchez de la Blanca and I. Carrillo, Synth. Met., 2008, 158, 165.

6 Except for a few, seemly unreliable, high values of conductivity that are discussed in ESI.

7 (a) G. Zotti and G. Schiavon, Synth. Met., 1990, 39, 183; (b) J. P. Ferraris and T. R. Hanlon, Polymer, 1989, 30, 1319. 
8 M.-a. Sato, S. Tanaka and K. Kaeriyama, J. Chem. Soc., Chem. Commun., 1985, 713.

9 J. K. Politis, J. C. Nemes and M. D. Curtis, J. Am. Chem. Soc., 2001, 123, 2537.

10 (a) M. J. González-Tejera and I. Carrillo, J. Appl. Electrochem., 2002, 32, 447; (b) X.-B. Wan, L. Li, J.-B. He, D.-S. Zhou, G. Xue and T.-W. Wang, J. Appl. Polym. Sci., 2002, 86, 3160; (c) S. Tirkeş and A. M. Önal, J. Appl. Polym. Sci., 2007, 103, 871. 11 (a) G. Zotti, G. Schiavon, N. Comisso, A. Berlin and G. Pagani, Synth. Met., 1990, 36, 337; (b) S. Glenis, M. Benz, E. LeGoff, J. L. Schindler, C. R. Kannewurf and M. G. Kanatzidis, J. Am. Chem. Soc., 1993, 115, 12519; (c) X. Wan, F. Yan, S. Jin, X. Liu and G. Xue, Chem. Mater., 1999, 11, 2400; (d) C. Liu, J. Zhang, G. Shi and Y. Zhao, J. Phys. Chem. B, 2004, 108, 2195.

12 (a) G. Tourillon and F. Garnier, J. Electroanal. Chem., 1982, 135, 173; (b) T. Ohsawa, K. Kaneto and K. Yoshino, Jpn. J. Appl. Phys., 1984, 23, L663.

13 (a) G. Shi, S. Jin, G. Xue and C. Li, Science, 1995, 267, 994; (b) W. Chen and G. Xue, Prog. Polym. Sci., 2005, 30, 783.

14 O. Gidron, Y. Diskin-Posner and M. Bendikov, J. Am. Chem. Soc., 2010, 132, 2148.

15 (a) A. Gandini, Adv. Polym. Sci., 1977, 25, 47; (b) E. T. Kang and K. G. Neoh, Eur. Polym. J., 1987, 23, 719; (c) R. M. McConnell, W. E. Godwin, S. E. Baker, K. Powell, M. Baskett and A. Morara, Int. J. Polym. Mater., 2004, 53, 697.

16 (a) P. A. Peart and J. D. Tovar, Macromolecules, 2009, 42, 4449;

(b) J. C. Bijleveld, B. P. Karsten, S. G. J. Mathijssen, M. M. Wienk, D. M. de Leeuw and R. A. J. Janssen, J. Mater. Chem., 2011, 21, 1600; (c) A. T. Yiu, P. M. Beaujuge, O. P. Lee, C. H. Woo, M. F. Toney and J. M. J. Fréchet, J. Am. Chem. Soc., 2012, 134, 2180; (d) P. Sonar, T. R. B. Foong, S. P. Singh, Y. Li and A. Dodabalapur, Chem. Commun., 2012, 48, 8383.

17 (a) U. H. F. Bunz, Angew. Chem., Int. Ed., 2010, 49, 5037; (b) X.-H. Jin, D. Sheberla, L. J. W. Shimon and M. Bendikov, J. Am. Chem. Soc., 2014, 136, 2592; (c) F. P. V. Koch, M. Heeney and P. Smith, J. Am. Chem. Soc., 2013, 135, 13699; (d) B. Capozzi, E. J. Dell, T. C. Berkelbach, D. R. Reichman, L. Venkataraman and L. M. Campos, J. Am. Chem. Soc., 2014, 136, 10486.

18 (a) O. Gidron, A. Dadvand, Y. Sheynin, M. Bendikov and

D. F. Perepichka, Chem. Commun., 2011, 47, 1976; (b) O. Gidron, A. Dadvand, E. Wei-Hsin Sun, I. Chung, L. J. W. Shimon, M. Bendikov and D. F. Perepichka, J. Mater. Chem. C, 2013, 1, 4358; (c) L. Zhang, N. S. Colella, F. Liu, S. Trahan, J. K. Baral, H. H. Winter, S. C. B. Mannsfeld and A. L. Briseno, J. Am. Chem. Soc., 2013, 135, 844.

19 (a) M. N. Belgacem and A. Gandini, in Monomers, Polymers and Composites from Renewable Resources, ed. M. N. Belgacem and A. Gandini, Elsevier, Amsterdam, 2008, ch. 6, p. 115; (b) A. Gandini, Macromolecules, 2008, 41, 9491; (c) J. B. Binder and R. T. Raines, J. Am. Chem. Soc., 2009, 131, 1979; (d) A. Gandini, Green Chem., 2011, 13, 1061.

20 (a) M. Okada, K. Tachikawa and K. Aoi, J. Appl. Polym. Sci., 1999, 74, 3342; (b) F. Koopman, N. Wierckx, J. H. de Winde and H. J. Ruijssenaars, Proc. Natl. Acad. Sci. U. S. A., 2010, 107, 4919.

21 (a) T. Kauffmann, H. Lexy and R. Kriegesmann, Chem. Ber., 1981, 114, 3667; (b) H. Ishida, K. Yui, Y. Aso, T. Otsubo and F. Ogura, Bull. Chem. Soc. Jpn., 1990, 63, 2828.

22 T. Kauffmann, B. Greving, R. Kriegesmann, A. Mitschker and A. Woltermann, Chem. Ber., 1978, 111, 1330.

23 J. Heinze, J. Mortensen and K. Hinkelmann, Synth. Met., 1987, 21, 209.

24 J. F. Kang, J. D. Perry, P. Tian and S. M. Kilbey, Langmuir, 2002, 18, 10196.

25 (a) S. Patra, K. Barai and N. Munichandraiah, Synth. Met., 2008, 158, 430; (b) A. I. Melato, M. H. Mendonça and L. M. Abrantes, J. Solid State Electrochem., 2009, 13, 417; (c) E. Poverenov, M. Li, A. Bitler and M. Bendikov, Chem. Mater., 2010, 22, 4019.

26 T. Taerum, O. Lukoyanova, R. G. Wylie and D. F. Perepichka, Org. Lett., 2009, 11, 3230.

27 (a) C. Taliani and W. Gebauer, in Handbook of Oligo- and Polythiophenes, ed. D. Fichou, Wiley-VCH, 1998, ch. 7, p. 361; (b) J. Roncali, P. Blanchard and P. Frere, J. Mater. Chem., 2005, 15, 1589.

28 (a) O. Gidron, N. Varsano, L. J. W. Shimon, G. Leitus and M. Bendikov, Chem. Commun., 2013, 49, 6256; (b) O. Gidron, Y. Diskin-Posner and M. Bendikov, Chem.-Eur. J., 2013, 19, 13140.

29 S. Sharma, N. Zamoshchik and M. Bendikov, Isr. J. Chem., 2014, 54, 712.

30 S. S. Zade and M. Bendikov, Org. Lett., 2006, 8, 5243.

31 NIST Computational Chemistry Comparison and Benchmark Database, NIST Standard Reference Database Number 101, Release 15b, ed. D. Russell Johnson III, August 2011, http://cccbdb.nist.gov/.

32 (a) B. S. Lamb and P. Kovacic, J. Polym. Sci., Polym. Chem. Ed., 1980, 18, 2423; (b) I. Carrillo, E. S. de la Bianca, M. J. González-Tejera and I. Hernández-Fuentes, Chem. Phys. Lett., 1994, 229, 633.

33 V. Hernandez, F. J. Ramirez, G. Zotti and J. T. L. Navarrete, J. Chem. Phys., 1993, 98, 769.

34 (a) J. W. Thackeray, H. S. White and M. S. Wrighton, J. Phys. Chem., 1985, 89, 5133; (b) N. F. Sheppard, R. C. Tucker and C. Wu, Anal. Chem., 1993, 65, 1199; (c) M. Nishizawa and I. Uchida, Electrochim. Acta, 1999, 44, 3629.

35 G. Schiavon, S. Sitran and G. Zotti, Synth. Met., 1989, 32, 209. 36 (a) L. Groenendaal, G. Zotti, P. H. Aubert, S. M. Waybright and J. R. Reynolds, Adv. Mater., 2003, 15, 855; (b) Z. Pomerantz, M. D. Levi, G. Salitra, R. Demadrille, A. Fisyuk, A. Zaban, D. Aurbach and A. Pron, Phys. Chem. Chem. Phys., 2008, 10, 1032; (c) M. Erginer, E. Sezer, B. Ustamehmetoğlu and J. Heinze, Electrochim. Acta, 2012, 67, 181.

37 Heraeus Clevios ${ }^{\mathrm{TM}} \mathrm{P}$ standard dispersion, http:// clevios.com/.

38 J. Roncali, F. Garnier, M. Lemaire and R. Garreau, Synth. Met., 1986, 15, 323.

39 C. Kvarnström, H. Neugebauer, S. Blomquist, H. J. Ahonen, J. Kankare and A. Ivaska, Electrochim. Acta, 1999, 44, 2739. 
40 A. A. Pud, Synth. Met., 1994, 66, 1.

41 (a) D. Zhang, J. Qin and G. Xue, Synth. Met., 1999, 100, 285;

(b) G. Tsekouras, C. O. Too and G. G. Wallace, Synth. Met., 2007, 157, 441.

42 M. Can, K. Pekmez, N. Pekmez and A. Yildiz, J. Appl. Polym. Sci., 2000, 77, 312.

43 (a) M. A. Invernale, Y. Ding, D. M. D. Mamangun, M. S. Yavuz and G. A. Sotzing, Adv. Mater., 2010, 22, 1379; (b) W. Yu, B. Xu, Q. Dong, Y. Zhou, J. Zhang, W. Tian and B. Yang, J. Solid State Electrochem., 2010, 14, 1051; (c) R. Schroeder, L. A. Majewski, M. Grell, J. Maunoury, J. Gautrot, P. Hodge and M. Turner, Appl. Phys. Lett., 2005, 87, 113501.

44 D. A. Rider, K. D. Harris, D. Wang, J. Bruce, M. D. Fleischauer, R. T. Tucker, M. J. Brett and J. M. Buriak, ACS Appl. Mater. Interfaces, 2008, 1, 279.

45 (a) S.-C. Luo, E. Mohamed Ali, N. C. Tansil, H.-h. Yu, S. Gao, E. A. B. Kantchev and J. Y. Ying, Langmuir, 2008, 24, 8071; (b)
E. Ventosa, J. L. Palacios and P. R. Unwin, Electrochem. Commun., 2008, 10, 1752.

46 C. Xia, X. Fan, M.-k. Park and R. C. Advincula, Langmuir, 2001, 17, 7893.

47 (a) W. Yu, T. Yao, X. Li, T. Wang, H. Gao, J. Zhang and B. Yang, J. Appl. Polym. Sci., 2011, 119, 1052; (b) V. Cocchi, L. Guadagnini, A. Mignani, E. Salatelli and D. Tonelli, Electrochim. Acta, 2011, 56, 6976.

48 A. Yassar, J. Roncali and F. Garnier, Macromolecules, 1989, 22, 804.

49 P. J. Brown, D. S. Thomas, A. Köhler, J. S. Wilson, J.-S. Kim, C. M. Ramsdale, H. Sirringhaus and R. H. Friend, Phys. Rev. B: Condens. Matter, 2003, 67, 064203.

50 (a) R. D. McCullough and R. D. Lowe, J. Chem. Soc., Chem. Commun., 1992, 70; (b) R. D. McCullough, R. D. Lowe, M. Jayaraman and D. L. Anderson, J. Org. Chem., 1993, 58, 904. 